\title{
Serum Lactate Dehydrogenase as a prognostic marker in preeclampsia and eclampsia
}

\author{
Hemalatha. K .R ${ }^{1,}$ Sahaja.Kittur, ${ }^{2, *}$ \\ ${ }^{1}$ Associate Professor, ${ }^{2}$ Assisstant Professor, Dept. of Obstetrics and Gynaecology, Karnataka Institute of Medical Sciences, \\ Hubballi, Karnataka, India \\ *Corresponding Author: \\ Email: drsahajakittur@ rediffmail.com
}

\begin{abstract}
Introduction: Hypertensive disorders of pregnancy are major contributor of maternal and perinatal mortality and morbidity. Several laboratory paramerters like AST, ALT, uric acid, LDH are evaluated to study the seriousness of the disease. Aim of this study was to evaluate the effectiveness of serum lactate dehydrogenase as a prognostic marker in pre eclampsia and eclampsia. Materials and Methods: This study was undertaken in Dept of OBG KIMS Hubli for a period of six months from November 2016 to April 2017. It was a prospective comparative case control study. A total of 130 women were enroled for the study. Out of 130 women, 30 women were considered as controls and they were normotensives. Out of remaining 100 who served as cases, 79 women were cases of preeclampsia and 21 women were cases of eclampsia.

Results: Preeclampsia and eclampsia were associated with higher levels of LDH .Adverse maternal and foetal outcome were noted in women with higher LDH values.

Conclusion: Increased levels of LDH are associated with severity of the disease and adverse maternal and foetal outcome. So LDH levels can act as a prognostic marker in preeclampsia and eclampsia.
\end{abstract}

Keywords: Eclampsia, Outcome, Pre eclampsia, Prediction, Prognosis, Serum Lactate Dehydrogenase.

\section{Introduction}

Preeclampsia is considered as idiopathic multisystem disorder that is specific to human pregnancy. ${ }^{1}$ Preeclampsia and eclampsia complicate 6$8 \%$ of all pregnancies and lead to various fetal and maternal complication. ${ }^{2}$ It carries substantial risk for both foetus and mother with subsequent increase in the perinatal and maternal morbidity and mortality.,4 Although the precise etiology of preeclampsia is not clear, defective placentation and endothelial dysfunction is the main aetiopathogenesis involved. ${ }^{1,4,5}$ Several potential candidate biochemical markers have been proposed to predict the severity of preeclampsia. ${ }^{6}$ Among these biochemical markers, LDH is conferred as good marker associated with severe preeclampsia. ${ }^{7}$ $\mathrm{LDH}$ is an intracellular enzyme which converts lactic acid to pyruvic acid and its elevated levels indicate cellular death and leakage of enzymes from the cell. ${ }^{7}$ LDH is the earliest marker seen in blood during hypoxia and oxidative stress. Hypoxia in preeclampsia enhances glycolysis and increases $\mathrm{LDH} .{ }^{8}$ Quantitative analysis of LDH reflects the extent of cellular death and thereby severity of complications occurring in preeclampsia and eclampsia. This can be further used as help in making decisions regarding the management strategies to improve the maternal and foetal outcome. ${ }^{2}$ The aim of the study was to evaluate the effectiveness of serum lactate dehydrogenase as a prognostic marker in preeclampsia and eclampsia, thereby to improve maternal and fetal outcome in them.

\section{Material and Methods}

This study was carried out in Department of Obstetrics and Gynaecology, KIMS, Hubli for a period of 6 months from Nov 2016 to April 2017. This was a prospective comparative case control study.

130 pregnant women were included for the study, 30 women were normotensive pregnancies and served as controls. Out of remaining 100 women who were considered as cases, 79 women who were diagnosed as preeclampsia and 21 women with eclampsia. Cases and control were matched for age and parity.

These women were categorised in 3 groups depending on LDH level.

Group 1 included women with LDH $<600 \mathrm{IU} / \mathrm{L}$

Group 2 included women with LDH 600-800 IU/L

Group 3 included women with LDH > 800 IU/L

Women were included in the study if they satisfied the following criteria-Singleton pregnancy, Age 18-35 years, Gestational age $>24$ weeks. Women with thyroid disorder, chronic hypertension, epilepsy, renal disease, liver disease and connective tissue disorder were excluded from the study.

The patient particulars were entered in proforma. Various demographic and laboratory parameters were evaluated. Serum LDH levels was estimated by continuous spectrophotometric method. All women were followed till delivery and early postpartum periods and babies till early neonatal period. Complications like abruption, DIC, MODS, PPH, CVA were assessed and their association with LDH was evaluated. Perinatal mortality and morbidity were assessed and correlated with $\mathrm{LDH}$ values. 


\section{Statistical analysis}

It was done. Variables are described first and then compared with these groups using ANOVA and Chi square test. A $\mathrm{P}$ value $<0.05$ were considered significant.

\section{Results}

Table 1 shows distribution of patients with age and parity. The cases and control were matched for age and parity and thus not statistically significant $(\mathrm{P}>0.05)$.

Table 1

\begin{tabular}{|l|c|c|c|c|}
\hline \multicolumn{1}{|c|}{ Group } & Control & $\begin{array}{c}\text { Severe } \\
\text { preeclampsia }\end{array}$ & Eclampsia & P ratio \\
\hline Number & 30 & 79 & 21 & \\
\hline Age (yrs) & $23.4+/-4.04$ & $23+/-3.9$ & $22.3+/-$ & $\mathrm{P}>0.05(\mathrm{NS})$ \\
Mean +/-SD & & & 3.35 & \\
\hline $\begin{array}{l}\text { Parity } \\
\text { Mean +/-SD }\end{array}$ & $1.8+/-1.22$ & $1.5+/-0.93$ & $1.1+/-0.44$ & $\mathrm{P}>0.05(\mathrm{NS})$ \\
\hline
\end{tabular}

Table 2 shows correlation of various groups with LDH values. All 30 women taken as controls had serum LDH $<600 \mathrm{IU} / \mathrm{L}$. Out of 79 women with severe preeclampsia, 60 women $(75.9 \%)$ had LDH values > 800 IU/L i.e belonged to group 3.8 women $(10.1 \%)$ belonged to group 1 and 11(13.9\%) women belonged to group 2. Out of 21 women with eclampsia, 18 women $(85.7 \%)$ had LDH values $>800 \mathrm{IU} / \mathrm{L}$ e belonged to group 3 and 3 women $(14.2 \%)$ had e belonged to group 2. None of the eclampatic women had LDH $<600 \mathrm{IU} / \mathrm{L}$.

Table 2: Correlation of various groups with $L D H$ values

\begin{tabular}{|l|c|c|c|c|c|c|c|}
\hline \multicolumn{1}{|c|}{ Group } & \multicolumn{2}{c|}{$\begin{array}{c}<600 I U / L \\
\text { (Grp I) }\end{array}$} & \multicolumn{2}{c|}{$\begin{array}{c}\text { 600-800IU/L } \\
\text { (Grp II) }\end{array}$} & \multicolumn{2}{c|}{$\begin{array}{c}>800 I U / L \\
\text { (GrpIII) }\end{array}$} & P Value \\
\hline & No. & \% & No. & \% & No. & $\%$ & \\
\hline $\begin{array}{l}\text { Control } \\
(\mathrm{n}=30)\end{array}$ & 30 & 100 & - & - & - & - & \\
\hline $\begin{array}{l}\text { Severe Preeclampsia } \\
(\mathrm{n}=79)\end{array}$ & 8 & 10.1 & 11 & 13.9 & 60 & 75.9 & \\
\hline Eclampsia(n=21) & 0 & 0 & 3 & 14.2 & 18 & 85.7 & \\
\hline Total cases & 38 & - & 14 & - & 78 & - & $\begin{array}{c}\text { P<0.0001** } \\
\text { highly } \\
\text { significant }\end{array}$ \\
\hline
\end{tabular}

Table 3 shows mean LDH values in various groups. The mean LDH values were definitely increased in severe preeclampsia and eclampsia which was highly significant $(\mathrm{P}<0.001)$.

Table 3: Mean LDH values in various groups

\begin{tabular}{|l|c|c|}
\hline \multicolumn{1}{|c|}{ Group } & LDH(mean+/-SD) IU/L & P Value \\
\hline Control(n=30) & $382.6+/-121.5$ & \\
\hline Severe & $1248.86+/-756.33$ & \\
Preeclampsia(n=79) & & $\begin{array}{c}\mathrm{P}<0.001 * * \\
* *\end{array}$ \\
\hline Eclampsia(n=21) & $1135.7+/-347.2$ & $* *$ Highly significant \\
\hline
\end{tabular}

Out of 38 women in group 1, 30 women(78.9\%) had normal systolic BP, 6 women(15.7\%) had systolic BP 140$159 \mathrm{~mm} \mathrm{Hg}$ and 2 women(5.2\%) had systolic BP > $160 \mathrm{mmHg}$. Out of 14 women in group 2, 1(7.1\%) had normal systolic BP, 6 women(42.8\%) had systolic BP of 140-159 mmHg and 7 women(50\%)had systolic BP > $160 \mathrm{mmHg}$. Out of 78 women in group 3, 10 women(12.8\%) had normal systolic BP, 43 women(55.1\%) had systolic BP 140$159 \mathrm{mmHg}$ and 25 women(32\%) had systolic BP > $160 \mathrm{mmHg}$. (Fig. 1) 


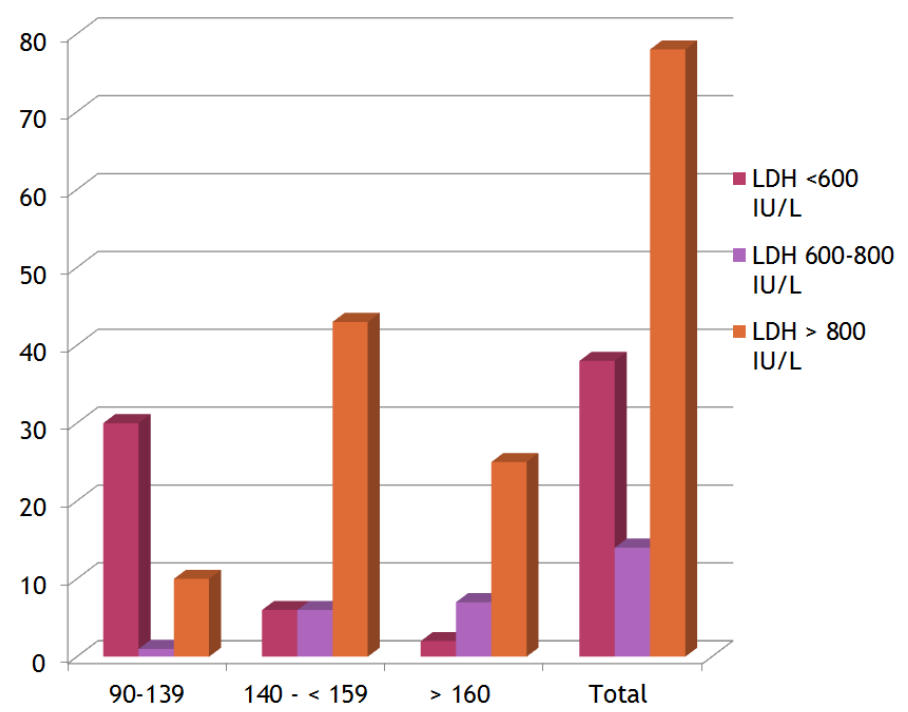

Fig. 1: Association of systolic blood pressure with LDH values

Similarly, out of 38 women in group 1, 30 women (78.9\%) had normal diastolic BP, 7 women (18.4\%) had diastolic BP in the range of $90-<110 \mathrm{mmHg}$ and 1 women $(2.6 \%)$ had diastolic BP $>110 \mathrm{mmHg}$. Out of 14 women in group 2, none had normal diastolic BP, 10 women (71.4\%) had diastolic BP in the range of $90-<110 \mathrm{mmHg}$ and 4 women $(28.5 \%)$ had diastolic BP > $110 \mathrm{mmHg}$. In the remaining 78 women in group 3, 6 women $(7.6 \%)$ had normal diastolic BP, 58 women (74.3\%) had diastolic BP in the range of $90-<110 \mathrm{mmHg}$ and 14 women (17.9\%) had diastolic $\mathrm{BP}>110 \mathrm{mmHg}$. (Fig. 2)

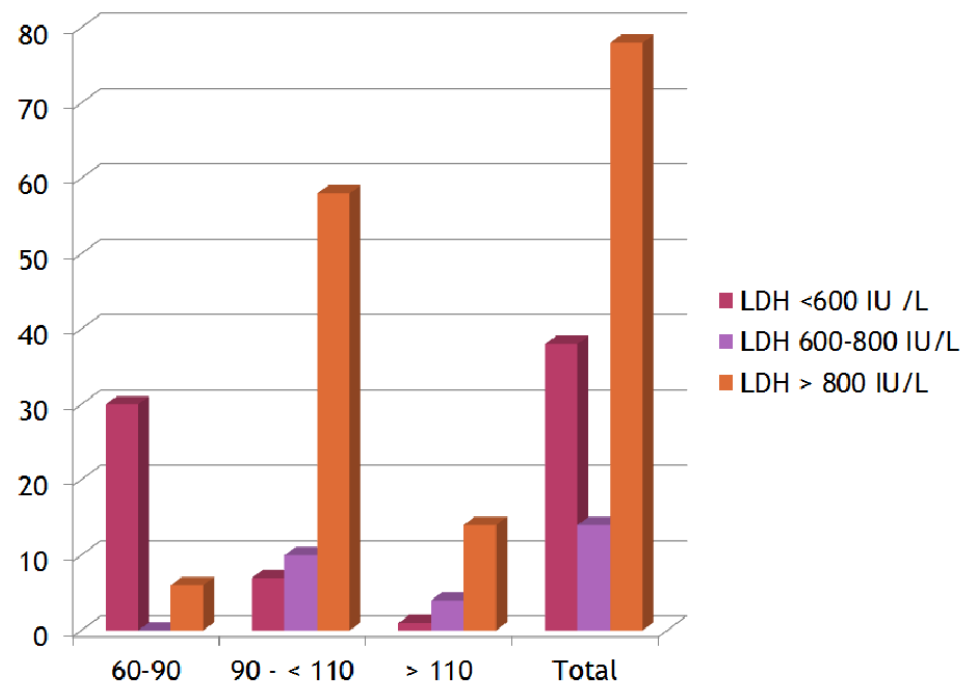

Fig. 2: association of diastolic blood pressure with $L D H$ values

Higher levels of serum LDH were associated with high systolic and diastolic BP $(\mathrm{p}<0.0001)$.

Perinatal outcome like mean gestational age, birth weight, sick babies requiring NICU care and perinatal mortality was studied and correlated with LDH values. The mean gestational age in group 1 was $38.8 \pm 2.13$ weeks, in group 2 it was $38.2 \pm 1.49$ weeks and in group 3 it was $35.0 \pm 4.02$ weeks (Fig. 3). These findings infer that as the serum LDH values increases the gestational age at birth decreased which was statistically significant. 


\section{Gestational age at birth (in weeks)}

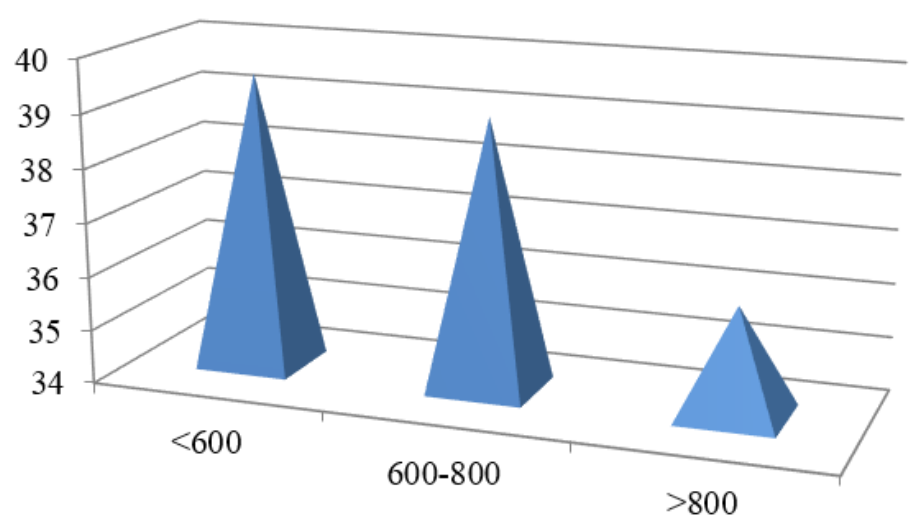

Fig. 3: correlation of gestational age with LDH values

In women belonging to Group 1,94.7\% were healthy and alive babies, $5.2 \%$ babies were sick requiring NICU care. In group $2,78.5 \%$ were healthy babies, $14.2 \%$ were sick babies. Where as in group 3, 39.7\% were healthy babies, $16.6 \%$ were sick babies.

$18.4 \%$ babies had birth weight $<2.5 \mathrm{~kg}$ in group 1 where as in Group 2, 50\% babies had birth weight less than $2.5 \mathrm{~kg}$ and, $80.7 \%$ babies in Group 3 had birth weight less than $2.5 \mathrm{~kg}$. This observation indicates that there is significant reduction in birth weight in women with higher LDH values $(\mathrm{P}<0.0001)$.

Group 1 had no still births or neonatal deaths. Group 2 had 1 early neonatal death whereas in Group 3, 12 neonatal deaths, 10 still births and 12 IUD occurred. Thus there is increase in both perinatal morbidity and mortality. These observations indicate that perinatal mortality and morbidity increases with increasing LDH levels. (Table 4).

Table 4:

\begin{tabular}{|l|l|l|l|l|}
\hline \multicolumn{1}{|c|}{ Parameters } & \multicolumn{1}{c|}{ Group 1 } & \multicolumn{1}{c|}{ Group 2 } & \multicolumn{1}{c|}{ Group 3 } & \multicolumn{1}{c|}{ P Value } \\
\hline Mean gestational age(weeks) & $38.8+/-2.13$ & $38.2+/-1.49$ & $35.0+/-4.02$ & $\mathrm{P}<0.0005^{*}$ \\
\hline $\begin{array}{l}\text { Birth weight } \\
<2.5 \mathrm{Kg}\end{array}$ & $7(18.4 \%)$ & $7(50 \%)$ & $66(80.4 \%)$ & $\mathrm{P}<0.0001^{* *}$ \\
\hline Birth weight $>2.5 \mathrm{Kg}$ & $31(81.5 \%)$ & $7(50 \%)$ & $15(19.2 \%)$ & $\mathrm{P}<0.0001^{* *}$ \\
\hline Alive with healthy baby & $36(94.7 \%)$ & $11(78.5 \%)$ & $31(39.7 \%)$ & $\mathrm{P}<0.0001^{* *}$ \\
\hline Sick baby & $2(5.2 \%)$ & $2(14.2 \%)$ & $13(16.6 \%)$ & $\mathrm{P}<0.005^{*}$ \\
\hline NND & - & $1(7.14 \%)$ & $12(15.3 \%)$ & \\
\hline Still birth & - & - & $10(12.8 \%)$ & \\
\hline IUD & - & - & $12(15.3 \%)$ & \\
\hline
\end{tabular}

Fig. 4 shows correlation of maternal outcome with LDH values. Group 1 had only 1 patient with post partum haemorrhage (PPH) and no other maternal complications. In women belonging to group, had 1 case of HELLP syndrome, 1 case of eclampsia (7.14\%) and 2 cases of PPH (14.2\%). In women belonging to group 3, complications were observed in 32 cases $(41 \%)$. Complications included 7 cases $(8.9 \%)$ of abruption, 9 cases $(11.5 \%)$ of PPH, 3 cases $(3.8 \%)$ of eclampsia, 2 cases $(2.5 \%)$ each of renal failure, posterior reversible encephalopathy syndrome(PRES), acute respiratory distress, disseminated intravascular coagulation(DIC) and 1 case (1.2\%) of multiorgan dysfunction syndrome (MODS). There were also 2 maternal deaths in this group, their LDH values being 4054IU/L and 1178IU/L.

This observation signifies that maternal complications were increased in women with increased serum LDH levels which was statistically highly significant $(\mathrm{P}<0.0001)$. 


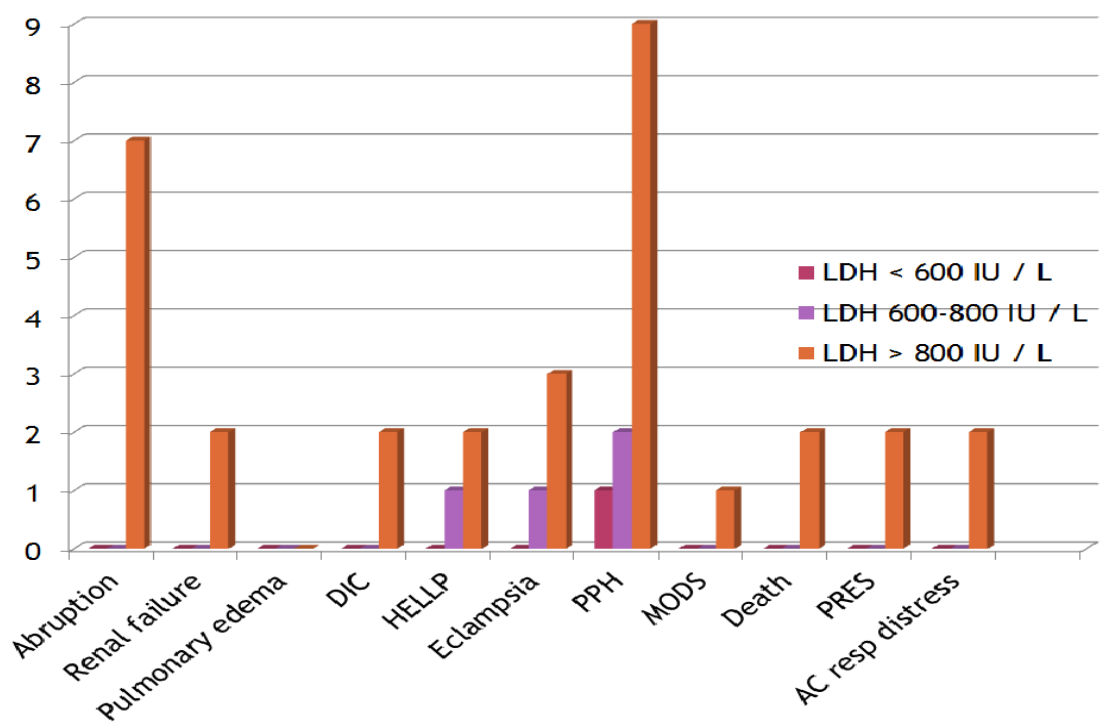

Fig. 4: Association of maternal complications with LDH values

\section{Discussion}

In this study,mean age among controls ,preeclampsia and eclampsia were $23.4+/-4.04$ years, $23+/-3.9$ years, 22.3+/-. Young age and primigravida are well known pre disposing factors for preeclampsia and eclampsia. Qublan et.al, Ali et.al, and Demir et.al also reported similar data in their respective studies. ${ }^{7,9,10}$

In our study the mean value of LDH was higher in preeclampsia and eclamosia compared to controls. Thus high LDH levels corresponds to the increasing severity of the disease. The Mean LDH values in various studies were:

Table 5

\begin{tabular}{|l|c|c|c|c|}
\hline \multicolumn{1}{|c|}{ Author } & Control & $\begin{array}{c}\text { Mild } \\
\text { Preeclampsia }\end{array}$ & $\begin{array}{c}\text { Severe } \\
\text { preeclampsia }\end{array}$ & Eclampsia \\
\hline Qublan et.al $^{7}$ & $299+/-79$ IU/L & $348+/-76$ IU/L & $774+/-69.6$ IU/L & - \\
\hline Jaiswar et.al $^{2}$ & $278.3+/-119.2$ & $400.45+/-145.2$ & $646.95+/-404.16$ & $1648.1+/-$ \\
& IU/L & IU/L & IU/L & $1772.2 \mathrm{IU} / \mathrm{L}$ \\
\hline Umasatyasri & $156.06+/-$ & $323.30+/-77.40$ & $636.20+/-$ & $649.32+/-$ \\
et.al $^{11}$ & $41.93 \mathrm{IU} / \mathrm{L}$ & $\mathrm{IU} / \mathrm{L}$ & $139.29 \mathrm{IU} / \mathrm{L}$ & $153.53 \mathrm{IU} / \mathrm{L}$ \\
\hline Our study & $382.6+/-121.5$ & - & $1248.86+/-$ & $1135.7+/-$ \\
& $\mathrm{IU} / \mathrm{L}$ & & $756.3 \mathrm{IU} / \mathrm{L}$ & $347.2 \mathrm{IU} / \mathrm{L}$ \\
\hline
\end{tabular}

Mean LDH values in eclampsia was lesser than severe preeclampsia in our study as we had only 21 cases of eclampsia and 79 cases of preeclampsia.

In study by Dave et.al. ${ }^{8} 84.3 \%$ of preeclampsia and $97.03 \%$ of eclampsia had LDH levels $>600 \mathrm{IU} / \mathrm{L}$. In present study LDH levels $>600 \mathrm{IU} / \mathrm{L}$ was seen in $89.8 \%$ of preeclampsia and $100 \%$ in eclampsia.

Both systolic and diastolic BP were found to be higher in women with higher LDH values. Study by Ali.et.al and Demir et.al have also had similar findings. ${ }^{9,10}$

Mean gestational age at delivery in patients with $\mathrm{LDH}>800 \mathrm{IU} / \mathrm{L}$ was $35.0+/-4.02$ weeks in our study. Similar findings have been observed in a study by Jaiswar et. al in whom mean gestational age at delivery in patients with $\mathrm{LDH}>800 \mathrm{IU} / \mathrm{L}$ was $35.25+/-3.23$ weeks in. ${ }^{2}$ In our study the birth weight was also reduced in patients with higher LDH values. Group 3 had, $80.7 \%$ of babies with birth weight $<2.5 \mathrm{~kg}$ and
$19.2 \%$ of babies with birth weight $>2.5 \mathrm{~kg}$. Similar result was found in a study by Dave et. $\mathrm{al}^{8}$ Qublan et. $\mathrm{al}^{7}$ has not found any association with birth weight and LDH values.

In our study perinatal morbidity was increased in women with higher LDH values, the perinatal death being $28 \%$. In a s tudy by Qublan ${ }^{7}$ and Jaiswar et.al, ${ }^{2}$ have also shown increase in perinatal mortality and morbidity in women with higher LDH values. Qublan ${ }^{7}$ noted perinatal death in $61.5 \%$.

Severe preeclamptic and eclamptic women with serum $\mathrm{LDH}>800 \mathrm{IU} / \mathrm{L}$ showed significant increase in maternal complications like abruption, $\mathrm{PPH}$, renal failure, DIC, PRES, HELLP and MODS when compared to women with low LDH values. Maternal mortality occurred in 2 women in whom the LDH values were $4054 \mathrm{IU} / \mathrm{L}$ and $1178 \mathrm{IU} / \mathrm{L}$. The women with LDH of $4054 \mathrm{IU} / \mathrm{L}$ had died due to MODS, thus 
signifying importance of $\mathrm{LDH}$ values in predicting adverse maternal outcomes.

Studies by Qublan et.al, Demir et. al and Martin et, ${ }^{2,10,12}$ all have also shown statistically significant relationship between maternal complications and high LDH values.

\section{Conclusion}

Serum lactate dehydrogenase acts as a useful prognostic marker in detecting complications of preeclampsia and eclampsia .Serum lactate dehydrogenaseas a biochemical marker is economical, easilyavailable test which can be offered to all the patients with hypertensive disorders in pregnancy. $B y$ identifying patients with raised $L D H$ values decision can be taken regarding their management and thus reduce the global burden of adverse outcomes in preeclampsia and eclampsia.

\section{References}

1. Friedman S A, Schiff E, Emeis J J et.al (1995).biochemical corroboration of endothelial involvement in severe preeclampsia. Am J Obstet Gynaecol, 172,202-3.

2. Jaiswar S.P, Amrit G, Rekha S, Natu S.N et al (2011) Lactic dehydrogenase: a biochemical marker for PreeclampsiaEclampsia. The Journal of Obstetrics and Gynaecology of India, 61,645-8.

3. Lain K Y, Roberts J M, Contemporary concepts of the pathogenesis and management of preeclampsia. JAMA 2002, 287:3183-6.

4. Norwitiz E R, Hsu C D, Repke J T, Acute complications of pregnancy. Clin Obstet Gynaecol 2002,45:308-93.

5. Lim K H, Zhou Y, Janatpour M, Human cytotrophoblast differentiation/invasion is abnormal in preeclampsia. Am J Pathol 1997,151,1809-18.

6. Chavarria Olarte M E, Gonalez Gleason A, Lara Gonalez A L et.al, 2000. Plasma concentration of biochemical markers in preeclampsia and eclampsia and its association with the severity of the disease. Ginecol Obstet Mex 68,385-93.

7. Qublan HS, Amarun V, Bateiner O et al (2005) LDH as a biochemical marker of adverse pregnancy outcome in severe preeclampsia.

8. Dave Anupama, Maru Laxmi, Jain A (2014) LDH: A Biochemical marker for the prediction of adverse outcomes in preeclampsia and eclampsia. Journal of Obstetrics and Gynaecology of India (2016) 66 (1):23-9.

9. Ali B S, Ghafoorian J, Alizadeh Sm. Severe preeclampsia in Kerman, Iran, complications and outcomes. Med Sci Monit.2004;10(4):CR163-7.

10. Demir SC, Evruke C, Ozgunen FT, et.al. Factors that influences morbidity and mortality in severe preeclampsia,eclampsia and heamolysis, elevated liver enzymes, and low platelet count syndrome. Saudi Med J J2006 27(7); 1015-8.

11. Y. Umasatyashri, I. Vani, P. Shamita Role of LDH in preeclampsia-eclampsia as a prognostic marker: An observational study. International Archieves of Integrated medicine (9) (2015) 88-93.

12. Martin J N Jr, May W L, Magann E F. Early risk assessment of severe preeclampsia. Admission battery of symptoms and laboratory test to predict the likelihood of subsequent significant maternal morbidity. Am J Obstet Gynaecol 1999,180:1407-14. 